\title{
CALIBRATION OF MANGERUD'S BOUNDARIES
}

\author{
Adam Walanus \\ Department of Geoinformatics, AGH University of Science and Technology, al. Mickiewicza 30, 30-059 Kraków, Poland. \\ Corresponding author. Email: walanus@geol.agh.edu.pl.

\section{Dorota Nalepka} \\ W. Szafer Institute of Botany, Polish Academy of Sciences, Lubicz 46, 31-512 Kraków, Poland.
}

\begin{abstract}
The "calibration" of arbitrarily defined (in some sense, "conventional") ages, given in conventional radiocarbon years BP, is now becoming necessary because the term "radiocarbon age" is used less often in archaeological and Quaternary practice. The standard calibration procedure is inappropriate here because Mangerud's boundaries are not measurement results. Thus, another approach to the problem is proposed in order to model the natural situation of many, uniformly distributed, dated samples, which should be similarly divided by the original and "calibrated" boundary. However, the result depends on the value of the typical measurement error and is not unequivocal.
\end{abstract}

\section{THE PROBLEM}

From the early (precalibration) development era of the radiocarbon method, some well-established "dates" of global or regional events have existed in the literature. These "time horizons" summarize a considerable number of ${ }^{14} \mathrm{C}$ dates as well as lithological considerations. Mangerud's chronozone boundaries are probably the most important (Mangerud et al. 1974). Dates proposed as a summary of the cumulated knowledge on climate change in the Holocene and Late Glacial epochs have the sense of convention. But in fact, these are arbitrarily established dates, or "boundaries," to which individually recorded events should be referred. The notion of a "chronozone" is correct for the climate stage while its boundaries are set as the absolute age. However, when one considers the date of publication (1974) it is clear that the boundaries are given in ${ }^{14} \mathrm{C}$ years (Conv BP). A problem arises because Mangerud's chronozones have been used extensively up to the present day (Webb 2006; Anderson et al. 2007; Berglund et al. 2008; Haynes 2008; Rybníček and Rybníčková 2008; Sørensen 2008; Wanner et al. 2008; Niinemets and Hang 2009; Walker et al. 2009).

It should be noted that a "rounded-off" number is typical for any arbitrary reference value. The chronozones provide a good example here, with values such as 5000 or 10,000. Less round, however, are $8000,9000,11,000,12,000$, and 13,000 Conv BP. Even less so is 2500 Conv BP, but swift climate changes, ending with the Last Glacial, have forced the value of 11,800 to be referred to within a precision of hundreds of years.

"Calibrating" an arbitrarily defined age (e.g. 5000 Conv BP) is different from calibrating a typical ${ }^{14} \mathrm{C}$ date. The chronozone boundaries have essentially no error. In a sense, it is an arbitrary definition to give an unequivocal reference value.

For about half of Mangerud's boundaries, it is possible to simply determine the calibrated age from the calibration curve (second column in Table 1). The function $T_{\text {conv }}=f\left(T_{\text {cal }}\right)$ is one-to-one in many cases, with a total duration of $27 \%$ of calendar time over the last dozen millennia. However, not only due to the fact that 2 boundaries ( 2500 and 8000 Conv BP) produce essentially many calibrated dates, the general "calibration" should be used here, and the longer parts of the calibration curve, particularly around the boundary, transformed to cal BC. Also, chronozones are long in duration in comparison to the typical time span of the calibration curve wiggle. The boundary between 2 chronozones reflects considerably slower climate changes (perhaps excluding the Preboreal/Younger Dryas). Calibrated boundaries should not depend on a ${ }^{14} \mathrm{C}$ concentration that is strictly local in time. 
The "calibrated" age of the boundary has to reflect its original, ${ }^{14} \mathrm{C}$ conventional counterpart in as many aspects as possible.



Figure 1 The general idea of "calibration" of Mangerud's boundary, exemplified by 5000BP - SB/AT one. For each (calendar) year, the responding ${ }^{14} \mathrm{C}$ age is taken from the calibration curve and the measurement Gaussian curve is calculated (Figure 2) and multiplied by the Gaussian weight presented for that figure. Then, all the measured Gauss are totaled, and the median of probability densities is calculated, for the given measurement error and central position of Gaussian weight for the samples (here $3800 \mathrm{cal} \mathrm{BC}$ ). The obtained median values are plotted in Figure 3.

Table 1 Readouts from the plots (Figure 1) for selected $\sigma$, the proposal of the "general" value valid for any $\sigma$, and final proposal of "calibrated" values with "rounding off" applied (with one ambiguity at $7000 \mathrm{BC}$ ). The value $\sigma=0$ refers to the simple transformation of the precise conventional age according to the calibration curve, which sometimes gives a unique value (neglecting calibration curve error) and sometimes not (then including that error). Calibration curve applied: IntCal09 (Reimer et al. 2009).

\begin{tabular}{c|lrrr|cc}
\hline & \multicolumn{6}{|c}{ BC } \\
\hline Conv BP & $\sigma=0$ & $\sigma=20$ & $\sigma=50$ & $\sigma=100$ & "General” $\sigma$ & Rounded off \\
\hline 2500 & $760-550$ & 690 & 660 & 640 & 640 & 600 \\
5000 & 3780 & 3780 & 3780 & 3780 & 3780 & 3800 \\
8000 & $7400-6850$ & 7000 & 6960 & 6940 & 6940 & $6950(7000)$ \\
9000 & 8250 & 8250 & 8240 & 8220 & 8200 & 8200 \\
10,000 & $9650-9420(9450)$ & 9470 & 9500 & 9520 & 9540 & 9500 \\
11,000 & $11,120-11,000$ & 10,965 & 10,970 & 10,980 & 10,980 & 11,000 \\
11,800 & 11,740 & 11,740 & 11,730 & 11,715 & 11,720 & 11,700 \\
12,000 & 11,880 & 11,890 & 11,900 & 11,900 & 11,900 & 11,900 \\
13,000 & 13,570 & 13,560 & 13,580 & 13,600 & 13,600 & 13,600 \\
& $(13,900-13,200)$ & & & & & \\
\hline
\end{tabular}




\section{PROPOSED SOLUTION}

The method of defining (calibrating) Mangerud's boundaries, in terms of calendar age, is as follows. Let us assume a uniform distribution of samples at the calendar time axis. (It is worth mentioning that this is an assumption for a priori distribution of ages in the typical calibration procedure.) Since, at the moment, we are interested in one boundary (say 5000 Conv BP), we focus on samples distributed around the expected equivalent calibrated age, maybe 4000 or $3800 \mathrm{cal} \mathrm{BC}$.

Let us take samples of true age equal to the consecutive years: ... 4001, 4000, 3999, 3998 cal BC, ..., one sample per year. However, its weight in the following calculations will diminish, according to the bell curve (Figure 1), with the distance from the assumed cal BC boundary (e.g. $3800 \mathrm{cal} \mathrm{BC}$ for 5000 Conv BP). Equally, the samples should be distributed Gaussially, more densely at 3800 cal $\mathrm{BC}$, less densely at $2800 \mathrm{cal} \mathrm{BC}$, even less so at $1800 \mathrm{cal} \mathrm{BC}$, and so on. The choice of the bell curve for the weight is arbitrary here, and has no connection with the probability distribution of the conventional date. The $\sigma$ of the Gaussian weight is also arbitrarily chosen to be $1000 \mathrm{yr}$. It has been checked that the final result does not depend heavily on that choice. (For the 2500 Conv BP boundary, the weights are cut symmetrically because of the AD 1950 limit.)

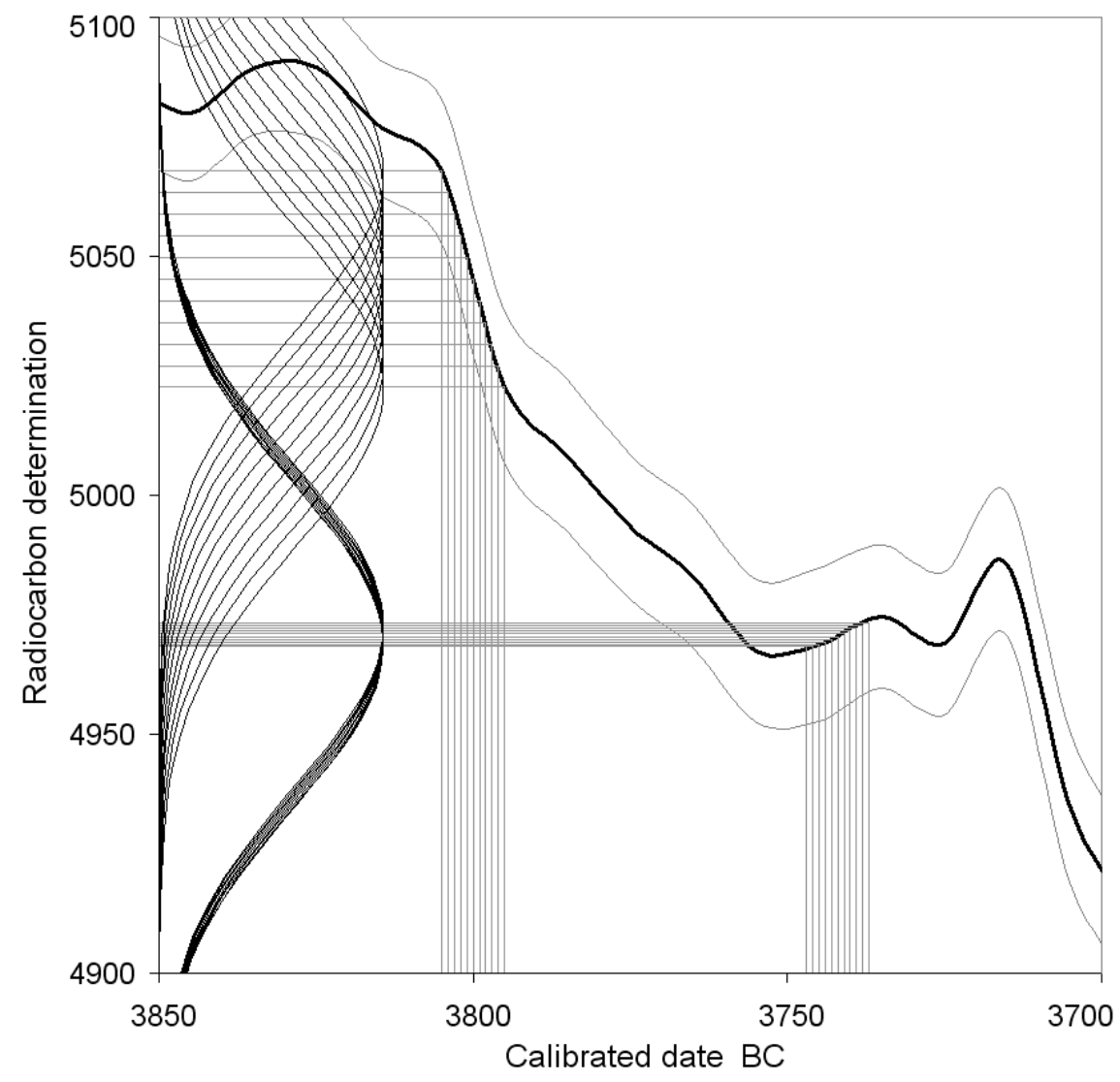

Figure 2 For each calendar year, the responding ${ }^{14} \mathrm{C}$ age is calculated and the Gaussian curve is obtained. All Gausses are totaled with the weight depending on calendar age (see Figure 1). Finally, the median of the sum is calculated. Only 2 groups of "samples" are presented for clarity (taken for extreme calibration curve slopes). 
Each sample is recalculated from the cal axis to the ${ }^{14} \mathrm{C}$ axis (Figure 2). For each sample, the typical measurement Gauss is obtained, with some measurement error $\sigma$. The amplitude of the probability density function is scaled down according to the weight indicated in Figure 1. All (weighted) Gaussian curves are totaled, and for the obtained function the median is found. That median is the final result, at that stage. Note that the result (radiocarbon age BP) is obtained for the assumed potential cal BC value for the given boundary (e.g. the aforementioned $3800 \mathrm{BC}$ ), and for the assumed date error $\sigma$. Calculations are performed for 20 values of $\sigma$ equally (logarithmically) distributed over 10 and $300 \mathrm{yr}$. The procedure is repeated for all sensible cal BC values for a 20 -yr sequence (...3800, 3820,3840 BC...).

Figure 3 shows the results of the calculations. Namely, the median Conv BP value is plotted as a function of the measurement $\sigma$, with the cal $\mathrm{BC}$ value representing the parameter of curves. According to the above, one median is recalculated to another median, which seems to be correct. The purpose of any boundary is to divide. If our aim is to recalculate Conv BP to cal $\mathrm{BC}$, the samples equally divided in the sense of Mangerud's Conv BP should also be equally divided in exactly same manner when their real time is considered.

\section{RESULTS}

A feature of the result given in Figure 3 is the non-negligible dependence on $\sigma$ (Walanus 2009). If the curves at the plot were flat, the final answer would be straightforward. Closest to that ideal is the Subboreal/Atlantic boundary at 5000 Conv BP, as well as that of the Older Dryas/Allerød at 11,800 Conv BP. Keeping in mind that the question of "rounding off" numbers is important here, the value of $3800 \mathrm{cal}$ BC seems to be a very good candidate for the "calibration" of 5000 Conv BP.

For 9000 Conv BP, the situation is not as promising, especially in comparison with the normal calibration result for that value (assuming $\sigma=0$, see Figure 3). In any case, despite the unique crossing of the calibration curve at $8246.5 \mathrm{cal} \mathrm{BC}$, which should be "rounded off" to $8250 \mathrm{cal} \mathrm{BC}$, the value $8200 \mathrm{cal} \mathrm{BC}$ seems to be a better solution. The "exact" value is valid only for a measurement error of zero and for very small errors. However, the realistic errors of ${ }^{14} \mathrm{C}$ determination $\left({ }^{14} \mathrm{C}\right.$ concentration measurement in the sample's proper chemical fraction) are larger (Buck et al. 2003; Scott et al. 2007).

Figure 3 is a pure result of calculations, performed under the numerical assumption of a $1000-\mathrm{yr}$ sigma for the Gaussian weight of the samples (Figure 1). However, plotted lines give no unique answer for the "calibration" of boundaries. Table 1 shows some values taken from the plots (Figure 3 ) as well as some generalizations, in the 2 far-right columns, separated from the objective values by a vertical line. The attempt to choose 1 value for the cal $\mathrm{BC}$ age, which would be universally accepted for any $\sigma$, is the most disputed point in the procedure. The subjective weights for different, practical, realistic values of $\sigma$ were applied. The idea of a "realistic" measurement error is connected with any possible "gross" errors as well as, for example, archaeological difficulties with the sample context. The next step, given in the last column of Table 1, i.e. that of "rounding off" numbers, is not so doubtful.

Table 2 shows the final proposal for the "calibration" of Mangerud's chronozones. There is only one difference in relation to the last column of Table 1, i.e. the subjective, deeper "rounding off" of the Boreal/Atlantic border.

The ambiguity of the proposed values is clearly visible in Figure 3 . The range defined in the columns " $\sigma=20$ " and " $\sigma=100$ " (Table 1) can be treated as error estimation for the given BC boundary. 


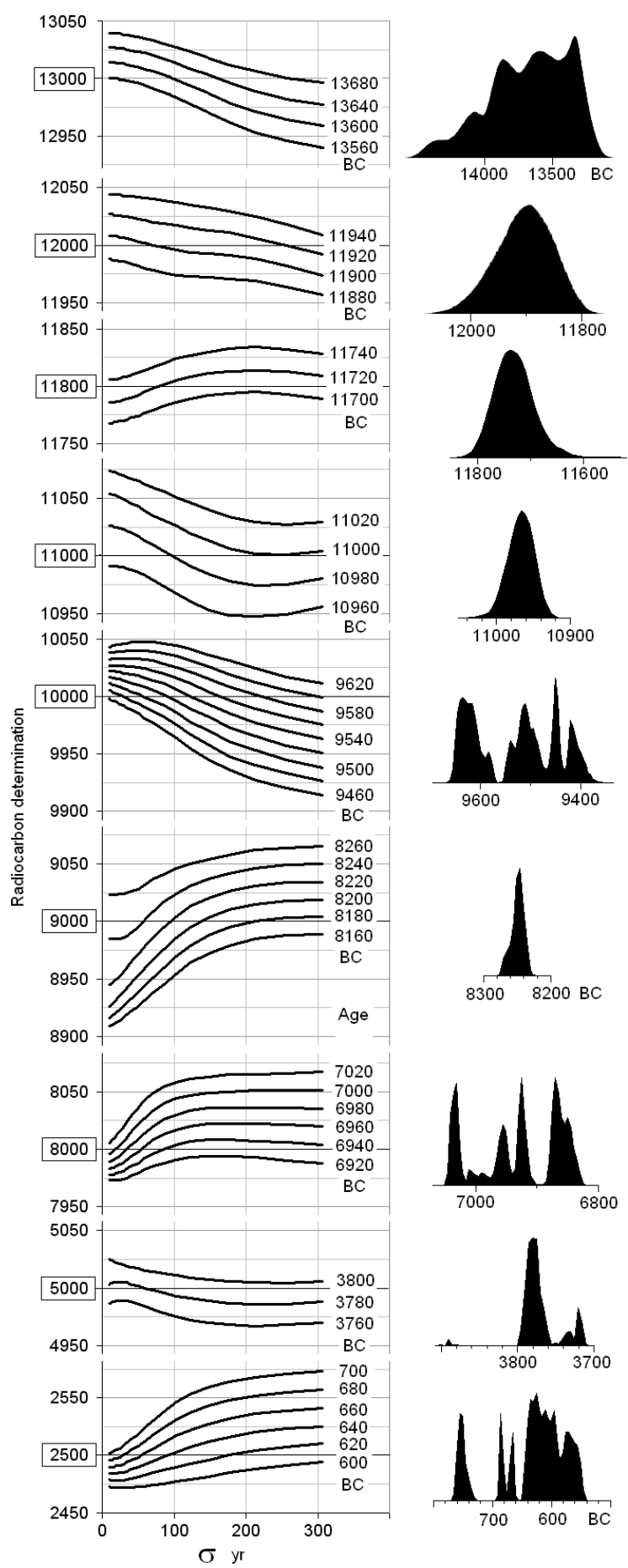

Figure 3 The ${ }^{14} \mathrm{C}$ (median) age as a function of the measurement error $\sigma$, for different calendar (BC) ages of the trial "center" of the large group of samples. Because lines are not strictly horizontal, the "calibration" of Mangerud's boundaries, in some cases only, is almost independent of $\sigma$. (The "conventional" description of the vertical axis is somehow incorrect here due to the different meanings of the word "determination.") Standard calibration (OxCal 4.1) of discussed boundaries, obtained with $\sigma=0$, is given for comparison purposes. 
Table 2 Final proposal for the "calibration" of Mangerud's chronozones.

\begin{tabular}{lcr}
\hline Boundary & Conv BP & \multicolumn{1}{c}{ BC } \\
\hline Subboreal / Subatlantic & 2500 & 600 \\
Atlantic / Subboreal & 5000 & 3800 \\
Boreal / Atlantic & 8000 & 7000 \\
Preboreal / Boreal & 9000 & 8200 \\
Younger Dryas / Preboreal & 10,000 & 9500 \\
Allerød / Younger Dryas & 11,000 & 11,000 \\
Older Dryas/ Allerød & 11,800 & 11,700 \\
Bølling / Older Dryas & 12,000 & 11,900 \\
Middle Glacial / Bølling & 13,000 & 13,600 \\
\hline
\end{tabular}

A confidence interval should be attached to any given range, with the confidence level associated roughly with the frequency of dates of $\sigma>100 \mathrm{yr}$, in a given project. However, it should be repeated that the idea of error or any imprecision is inconsistent with the idea of an arbitrary value. It would only be the question of an arbitrary decision as to which strict "calibrated" numbers are to replace the conventional ${ }^{14} \mathrm{C}$ ages of the Holocene and Younger Dryas boundaries.

\section{ACKNOWLEDGMENT}

This work was financed by Statutory Research.

\section{REFERENCES}

Anderson DE, Goudie AS, Parker AG. 2007. Global Environments through the Quaternary Exploring Environmental Change. New York: Oxford University Press. 359 p.

Berglund BE, Gaillard M-J, Björkman L, Persson T. 2008. Long-term changes in floristic diversity in southern Sweden: palynological richness, vegetation dynamics and land-use. Vegetation History and $\mathrm{Ar}$ chaeobotany 17(5):573-83.

Buck CE, Higham TFG, Lowe DJ. 2003. Bayesian tools for tephrochronology. The Holocene 13(5):639-47.

Haynes Jr V. 2008. Younger Dryas "black mats" and the Rancholabrean termination in North America. Proceedings of the National Academy of Sciences USA 105(18):6520-5

Mangerud J, Andersen ST, Berglund BE, Donner J. 1974. Quaternary stratigraphy of Norden, a proposal for terminology and classification. Boreas 3(3):109-26.

Niinemets E, Hang T. 2009. Ostracod assemblages indicating a low water level episode of Lake Peipsi at the beginning of the Holocene. Estonian Journal of Earth Sciences 58(2)133-47.

Reimer PJ, Baillie MGL, Bard E, Bayliss A, Beck JW, Blackwell PG, Bronk Ramsey C, Buck CE, Burr GS, Edwards RL, Friedrich M, Grootes PM, Guilderson TP, Hajdas I, Heaton TJ, Hogg AG, Hughen KA, Kaiser KF, Kromer B, McCormac FG, Manning SW, Reimer RW, Richards DA, Southon JR, Talamo S, Turney CSM, van der Plicht J, Weyhenmeyer CE. 2009. IntCa109 and Marine09 radiocarbon age calibration curves, 0-50,000 years cal BP. Radiocarbon 51(4): $1111-50$.
Rybníček K, Rybníčková E. 2008. Upper Holocene dry land vegetation in the Moravian-Slovakian boreland (Czech and Slovak Republics). Vegetation History and Archaeobotany 17:701-11.

Scott EM, Cook GT, Naysmith P, Bryant C, O’Donnell D. 2007. A report on Phase 1 of the 5th International Radiocarbon Intercomparison. Radiocarbon 49(2):40926.

Sørensen R. 2008. Late Weichselian deglaciation in the Oslofjord area, south Norway. Boreas 8(2):241-6.

Walanus A. 2009. Systematic bias of radiocarbon method. Radiocarbon 51(2):433-6.

Walker M, Johnsen S, Rasmussen SO, Popp T, Steffensen J-P, Gibbard P, Hoek W, Lowe J, Andrews J, Björck S, Cwynar LC, Hughen K, Kershaw P, Kromer B, Litt T, Lowe DJ, Nakagawa T, Newnham R, Schwander J. 2009. Formal definition and dating of the GSSP (Global Stratotype Section and Point) for the base of the Holocene using the Greenland NGRIP ice core, and selected auxiliary records. Journal of Quaternary Science 24(1):3-17.

Wanner H, Beer J, Bütikofer J, Crowley TJ, Cubasch U, Flückiger J, Goosse H, Grosjean M, Joos F, Kaplan JO, Küttel M, Müller SA, Prentice IC, Solomina O, Stocker TF, Tarasov P, Wagner M, Widmannm M. 2008. Mid- to Late Holocene climate change: an overview. Quaternary Science Reviews 27(19-20):1791828.

Webb SD, editor. 2006. First Floridians and Last Mastodons: The Page-Ladson Site in the Aucilla River. Topics in Geobiology 26. Dordrecht: Springer. 588 p. 